\title{
Predictors of dietary diversity among adults on antiretroviral therapy in Debre Tabor Hospital, northwest Ethiopia: A cross-sectional study
}

Kassaw Wubnew Zerihun

Debre Tabore health Science College

Esmael Ali Muhammad

University of Gondar

Gashaw Andargie Biks

University of Gondar

Aysheshim Kassahun Belew

University of Gondar

Melkamu Tamir Hunegnaw ( $\square$ melkamutamir@gmail.com )

University of Gondar,Ethiopia

Research article

Keywords: Dietary diversity, people live with HIV, Ethiopia

Posted Date: January 16th, 2020

DOI: https://doi.org/10.21203/rs.2.21041/v1

License: (9) This work is licensed under a Creative Commons Attribution 4.0 International License.

Read Full License 


\section{Abstract}

Background: Diversified diet to improve better tolerates human immunodeficiency virus drugs, enhance antiretroviral therapy adherence and maintain a healthy weight to reduce mortality and morbidity. Therefore, the aim of this study was to assess dietary diversity and associated factors among adult human immunodeficiency virus positive patients who were on antiretroviral therapy at Debre Tabor Hospital northwest Ethiopia

Methods: Institutional based cross-sectional study was conducted at Debre Tabor Hospital and participants selected by the systematic random sampling techniques. Data collection was done by using a structured interview questionnaire. Dietary diversity was computed from all food and drink list consumed in the 24 hours preceding the survey. A variable having $p$-value $<0.2$ in the bivariate logistic regression was entered into the multivariable logistic regression, and independent variables having $\mathrm{p}$ value $<0.05$ was considered as significantly associated.

Results: Of the total 341 adults on antiretroviral therapy 336 participants gave a complete response with a response rate of $98.50 \%$. Among the participants 336 [32.4\% (95\% Cl: 27.4, 37.1)] had adequate dietary diversity and $22.9 \%$ were $\mathrm{BMI}<18.5 \mathrm{~kg} / \mathrm{m}^{2}$. Government employment [AOR= $2.5 ; 95 \% \mathrm{Cl}: 1.28,4.98$ ) and diploma and above educational status $[\mathrm{AOR}=2.3 ; 95 \% \mathrm{Cl}: 1.01,5.31)$ were factors for adequate dietary diversity.

Conclusions: In this study the magnitude of adequate dietary diversity was low. Employment and educational status were significantly associated with dietary diversity among people living with HIV/AIDS. Hence, improving education status as well as income generation activities are highly recommended strategy to improve the dietary diversity of patients on antiretroviral therapy.

\section{Introduction}

Globally, 36.7 million people are living with HIV/AIDS (PLWHA) (1). Poor nutrition and HIV/AIDS are interrelated and aggravate each other in a vicious cycle by attacking the immune system(2). The nutritional status of an individual is affected by HIV/AIDS through increasing energy requirements, reducing food intake, and decreasing nutrient absorption and metabolism $(3,4)$. Having good nutritional status and eating diversified diets have an important role in enhancing antiretroviral therapy (ART), encouraging good adherence to ART drugs, and maintaining healthy weight (5).

HIV/AIDS attacks the immune system and make the body susceptible to opportunistic infections like fever, diarrhea, tuberculosis, pneumonia. Hence, adequate dietary intake alongside ART helps the immune system to be strong, and enable it to fight diseases better (6). On the other hand, undiversified diet can intake possibly contribute to micronutrient deficiencies that lead to HIV/AIDS progression and the depletion of the cluster of differentiation of the CD4 count which increases the risk of opportunistic infections in addition to oxidative stress $(7,8)$. 
Dietary diversity is the assessing qualitative utilization of food which reflects an individual's right use to different foods; it is also an indicator of a diet's micronutrient adequacy, an important dimension of its quality $(9,10)$. It even serves as a proxy indicator of diet quality and indicates its association with the nutrient adequacy of an individual's diet $(11,12)$.

Dietary diversity is a challenge to communities the cause their diets are mainly starchy staples with inadequate animal products, fruits, and vegetables (13). Utilizing diversified diet among PLHIV is still poor among resource limited nations like Africa. For instance, 58.8 and $62.3 \%$ of the PLHIV in Nigeria and Uganda $(14,15)$ received inadequate dietary diversity respectively while, $28.7-58.8 \%$ of adults obtained inadequate dietary diversity in Ethiopia $(13,16)$. Previous studies reported residence $(17)$, wealth index $(13,17)$, employment status (13), duration of ART treatment (16), owning mobile cell phones (18), media exposure status (18) and nutritional counseling (18) were factors affecting dietary diversity among adults living with HIV/AIDS.

Ethiopia has made a notable effort to address the impact of HIV/AIDS on nutrition by preparing national guidelines for HIV/AIDS and by taking actions to provide quality care and support to people living with the disease (19). In addition, it provided livelihood support and food assistance and strengthened community based nutrition care and support activities for PLHIV through health extension workers, agriculture extension workers, and health development armies, in addition to HIV/AIDS treatment, care, and support $(20,21)$. But, diversified diet is a serious unmoving problem among $29.5 \%$ of adults living with HIV/AIDS (18). Yet, there is little information regarding the effects of undiversified diet among PLHIV in Ethiopia, including the study setting $(16,18)$. Therefore, this study aimed to assess the prevalence and associated factors of dietary diversity among of HIV positive adults on ART attending at Debre Tabor hospital, northwest Ethiopia.

\section{Methods}

\section{Study design and settings}

An institutional based cross-sectional study was conducted to assess the predictors of dietary diversity among adult HIV/AIDS patients on ART at Debre Tabor hospital, northwest, Ethiopia. Debre Tabor hospital is located in South Gondar zone, northwest Ethiopia $667 \mathrm{~km}$ from Addis Ababa, capital of Ethiopia. The hospital provides service to more than 1,000,000 people by 253 health professionals. On average, 45 HIV/AIDS adult patients used to attend the ART Clinic per day. At the moment 1980 HIV/AIDS patients were on ART at the clinic; 1822 of the patients were adults.

\section{Sample size and sampling procedures}

Sample size was determined by the simple population proportion formula by considering the following assumptions; a 95\% confidence interval, marginal error of 5\%, and 58.8\% (13) proportion of inadequate dietary diversity which yielded a sample of 372 . However, as the source population was less than 10,000, we considered a population reduction formula plus a non-response rate of $10 \%$. The final sample size 
was then 341. Participants were selected by the systematic random sampling technique. According to the report from the hospital administration, the monthly average number of adult HIV/AIDS patients on ART

was 990 . The sampling interval $\left(\mathrm{k}^{\text {th }}\right)$ value was determined by dividing the total monthly adult patients by the sample size $(990 / 341=3)$. The first respondent was selected by the lottery method out of the first three clients. The procedure continued until the required sample size was obtained.

\section{Data collection methods and quality control}

Data were collected by a face to face interview using a structured questionnaire. The tool included socio demographic characteristics, clinical conditions, nutritional status, and dietary characteristics. Dietary diversity score was computed by asking the participants if they consumed all foods and drinks on the list in the preceding 24 hours of the survey according to the Food and Agriculture Organization (FAO) 2011(22). Likewise, the nutritional status of the participants was assessed by measuring weight and height and calculating Body Mass Index (BMI). BMI less than $18.5 \mathrm{~kg} / \mathrm{m}^{2}$ was considered as undernutrtion, while a BMI scale of $18.5-24.9$ and $\mathrm{BMI}>30 \mathrm{~kg} / \mathrm{m}^{2}$ were taken as normal and obesity, respectively(23).

To maintain data quality, training was provided to data collectors and supervisors for two days by the principal investigator. The training was related to how to approach participants ethically while interviewing them. A pre-test was conducted on $5 \%$ of the participants at Debre Tabor health center. The completeness, accuracy and consistency of the collected data were checked daily by an assigned responsible supervisor and the principal investigator.

\section{Measurements of dietary diversity score}

The dependant variable of this study is dietary diversity. Individual Dietary Diversity Score (IDDS) of the study participants was measured by adding the food groups consumed over the preceding 24 hours before the survey from starchy staples, pulse, nuts and seeds, dairy, meat, poultry and fish, eggs, dark green leafy vegetables, other vitamin A-rich fruits and vegetables, other vegetables and other fruits. If participants consumed five or more food groups out of the ten listed, they were considered to have an adequate dietary diversity score(22).The independents variables in this study include socio demographic characteristics, clinical conditions and nutritional status of the participants.

\section{Data analysis}

The collected data were entered, coded, and cleaned using Epi INFO version 7.0 and data management and analyses were performed using SPSS version 20.0 software. The association of dependent and independent variables was assessed by using the binary logistic regression and in the bivariable analysis variables with $p$ values $<0.2$ were entered into the multivariable logistic regression with $95 \%$ Confidence Intervals. The corresponding $p$ value of $<0.05$ was considered as statistically significant at a $95 \%$ confidence interval. 


\section{Result}

A total of 336 HIV positive adults on ART participated in the study with a response rate of $98.5 \%$ and a mean age $39.08 \pm 10.9$ SD. Of the total respondents, almost all (99.4\%) of respondents were Orthodox Christians and less than half (43.8\%) were married. Most, $(81.8 \%)$ of the respondents were urban dwellers; while $32.7 \%$ and $33 \%$ were college diploma graduates and government employees, respectively (Table 1).

More than half (58\%) of the respondents were in WHO clinical stage one, and about half (53\%) had CD4 count of greater than $500 \mathrm{mg} / \mathrm{mm}$, while nearly three-fourths (72.3\%) were taking ART for more than three years (Table 2).

\section{Factors associated with dietary diversity among HIV/AIDS patients on ART}

In the multivariate logistic regression analysis, educational and occupational statuses were significantly associated with adequate dietary diversity. Accordingly, patients who had diploma and above educational status were 2.3 times more likely to consume adequate diversified diet compared with those who were unable to read and write ( $\mathrm{AOR}=2.3,95 \% \mathrm{Cl}: 1.01,5.31)$. Likewise, higher odds of diversified diet were noted among government employees than among the unemployed (AOR=2.6, 95\%; Cl: 1.28, 4.98) (Table 3). The overall prevalence of adequate dietary diversity among adult HIV/AIDS patients on ART was $32.4 \%$ (95\% Cl: $27.4,37.1)$. The mean dietary diversity scores were 3.75 with 1.95 standard deviation.

\section{Discussion}

This study assessed the magnitude and predictors of dietary diversity among adult patients on ART. The overall prevalence of inadequate dietary diversity intake of the current study was $67.6 \%$. This finding was comparable with that of a study done in Hosanna town, southern Ethiopia, $(67.9 \%)(24)$; whereas, it was higher than those of studies done in Dembia (11.3\%) (25), Uganda (14.7\%) (26), Hiwot Fana and Dilchora hospital, eastern Ethiopia (28.7\%) (16), Metema (58.8\%) (13), and Nigeria (62.3\%) (14). This variation might be due to differences in study settings, seasons, socio-economic status of respondents and cut-off points used to ascertain the outcome variable. Our study also verified that only $3.9 \%$ of the participants ate eggs. This finding was supported by that of a study done in Nigeria (14). That is because eggs were too expensive compared with staple diets.

In this study, patients who had completed college and above were more likely to get adequate dietary diversity compared to the non-educated. This was in line with studies done in Jimma (27), Metema (13), Amatole and Nyandeni districts, South Africa (28). This is due to the fact that if patients level of education is low, their access to finance and their contribution to the total producing income will be low while good education creates employment opportunities to generate income to assure food security and improve purchasing capacity of diversified diet. The other possible reason might be that more educated participants get better service in terms of nutrition education and counseling to improve their nutritional information. Nutritional knowledge has a role to play in dietary practices and the number of meals based 
on their requirements $(29,30)$. Uneducated respondents may not understand the consequences of inadequate diversified diets easily $(30,31)$. Higher education is more likely to correlate with higher income to spend on a variety of foods (32). Furthermore, educated respondents have media exposure to improve their nutritional knowledge and allocate a larger proportion of their household food budget to food groups. This was supported by previous studies that participants who had exposure to the media were more likely to receive diversified diets $(33,34)$.

Employment status was the other factor significantly associated with dietary diversity in this study. Government employee HIV patients were 2.5 times more likely to consume adequately diverse diets than non-government employee patients on ART. This was supported by studies done in Jimma (27), Metema (13), and north India (35). The most possible explanation might be that government employees had regular income which they used to vary their food, while their counterparts had less chance of doing that. In addition, joblessness might be the result of how educational status which could result in poor wealth status that affects the capacity to purchase adequate and appropriate food. Besides, unemployed participants experienced food insecurity which decreased their capacity of consuming diverse diets at individual and household levels $(36,37)$.

\section{Conclusion}

This study showed that the prevalence of adequate dietary diversity was low. Government employment and diploma and above educational status were significantly associated with dietary diversity among adult people living with HIV/AIDS. Therefore, special emphasis on improving education status as well as income generation activities are highly recommended strategy to improve the dietary diversity of patients on antiretroviral therapy.

\section{Limitations Of The Study}

Although, this study has attempted to show factors affecting the dietary diversity of PLWHA, it has some limitations which should be taken into consideration. We didn't measure food weight to estimate calorie quantities in foods, and during measuring dietary diversity, recall bias was one of the likely constraints of the study. We also did not address seasonality when administering the FANTA HDDS questionnaire.

\section{List Of Abbreviations}

AIDS =Acquired Immune Deficiency Syndrome, AOR =Adjusted Odds Ratio, ART= Anti-Retroviral Therapy, $\mathrm{BMI}=$ Body Mass Index, CD4=Cluster of Differentiation4, COR=Crude Odds Ratio, DDS =Dietary Diversity Score, IDDS = Individual Dietary Diversity Score, FAO=Food and Agriculture Organization, GDP =Gross Domestic Product, HIV= Human Immune Deficiency Virus, MG=Milligram, MM=Milliliter, PLWHA=People Living with HIV/AIDS, SPSS =Statistical Package for Social Science, $\mathrm{WHO}=$ World Health Organization

\section{Declarations}




\section{Ethics approval and consent to participate}

Ethical clearance was obtained from Institute of Ethical Review Board of University of Gondar. An official permission letter was obtained Debre Tabor hospital. Written informed consent was obtained from study participants in their local language after explaining the purpose of the study, potential risks and benefits of the study, and the right to withdraw from the study at any time. The participants were also assured that the data was confidential.

\section{Consent for publication}

Not applicable.

\section{Availability of data and materials'}

Data will be available upon request from the corresponding authors.

\section{Funding}

No fund was obtained for this study

\section{Authors' contribution}

KW conceived the study, developed the tool, coordinated the data collection activity, and carried out the statistical analysis. EA, MTH and GA participated in the design of the study and tool development, performed statistical analysis, and reviewed the manuscript. AK involved in the tool development, and performed statistical analysis. All authors read and approved the final manuscript.

\section{Acknowledgements}

We would like to thank Debre tabor hospital for their support to conduct the study and for providing all the required information. We would also thank all respondents for their genuine response during the interviews and the data collectors as well as supervisors for their kind cooperation and strong commitment.

\section{Competing interests}

The Authors declare that they have no conflict of interest.

\section{References}

1. HIV/AIDS JUNPo. Global AIDS update 2016. Geneva: UNAIDS. 2016.

2. Stephen D. WORLD AIDS DAY the role of nutrition in living with HIV. AIDS (London, England). 2008:12-5. 
3. Daniel M, Mazengia F, Birhanu D. Nutritional status and associated factors among adult HIV/AIDS clients in Felege Hiwot Referral Hospital, Bahir Dar, Ethiopia. Science Journal of Public Health. 2013;1(1):24-31.

4. Piwoz E. Nutrition and HIV/AIDS: evidence gaps and priority actions. 2004.

5. Organization WH. Nutrient requirements for people living with HIV/AIDS: report of a technical consultation. Geneva: WHO. 2003.

6. Nanziri C. Factors associated with dietary intake among HIV positive adults (18-65 years) at the Mildmay Center, kampala, Uganda: Makerere University; 2010.

7. Jariwalla RJ, Niedzwiecki A, Rath M. Micronutrients and nutrient synergy in immunodeficiency and infectious disease. Botanical Medicine in Clinical Practice. 2008:203-12.

8. Kennedy G, Fanou-Fogny N, Seghieri C, Brouwer ID. Dietary diversity as a measure of the micronutrient adequacy of women's diets: results from Bamako, Mali site. Academy for Educational Development, 2009.

9. Kennedy G, Ballard T, Dop MC. Guidelines for measuring household and individual dietary diversity. Nutrition and consumer protection division, food and agriculture organization of the United Nations. 2011. Print; 2015.

10. Ruel MT. Is dietary diversity an indicator of food security or dietary quality? International Food Policy Research Institute (IFPRI), 2002.

11. Workicho A, Belachew T, Feyissa GT, Wondafrash B, Lachat C, Verstraeten R, et al. Household dietary diversity and Animal Source Food consumption in Ethiopia: evidence from the 2011 Welfare Monitoring Survey. BMC public health. 2016;16(1):1192.

12. FAO F. Minimum dietary diversity for women: a guide for measurement. Rome: FAO. 2016.

13. Amare TW, Melkie EY, Teresa KB, Melaku KY. Factors associated with dietary diversity among HIV positive adults ( $\geq 18$ years) attending ART clinic at Mettema hospital, Northwest Ethiopia: crosssectional study. Journal of AIDS and Clinical Research. 2015;6(8).

14. Akwiwu UN, Akinbile LA. Dietary Intake Adequacy of People Living with HIV/AIDS in Rural Communities of Imo State, Nigeria. Journal of Agricultural Extension. 2017;21(1):218-30.

15. Bukusuba J, Kikafunda JK, Whitehead RG. Food security status in households of people living with HIV/AIDS (PLWHA) in a Ugandan urban setting. British Journal of Nutrition. 2007;98(1):211-7.

16. Weldegebreal F, Digaffe T, Mesfin F, Mitiku H. Dietary diversity and associated factors among HIV positive adults attending antiretroviral therapy clinics at Hiwot Fana and Dilchora Hospitals, eastern Ethiopia. HIV/AIDS (Auckland, NZ). 2018;10:63.

17. Masa R, Chowa G, Nyirenda V. Socioeconomic correlates of dietary diversity and its association with adherence and psychosocial functioning of people living with HIV in rural Zambia. Nutrition and health. 2018;24(2):93-102.

18. Tesfaw A, Jara D, Temesgen H. Dietary Diversity and Associated Factors among HIV Positive Adult Patients Attending Public Health Facilities in Motta Town, East Gojjam Zone, Northwest Ethiopia, 
2017. Advances in Public Health. 2018;2018.

19. The Federal Democratic Republic of Ethiopia Ministry of Health. National Guidelines for HIV/AIDS and Nutrition. 2008.

20. Federal Democratic Republic Of Ethiopia. Nationla Nutrition Progarm 2016-2020. 2016.

21. Federal Ministry Of Health. Nationla Guidelines for Comprehensive HIV Prevention , Care and Treatment 2017.

22. Kennedy G, Ballard T, Dop MC. Guidelines for measuring household and individual dietary diversity: Food and Agriculture Organization of the United Nations; 2011.

23. Bhurosy T, Jeewon R. Overweight and obesity epidemic in developing countries: a problem with diet, physical activity, or socioeconomic status? The Scientific World Journal. 2014;2014.

24. Asnakew M, Hailu C, Jarso H. Malnutrition and associated factors among adult individuals receiving highly active antiretroviral therapy in health facilities of Hosanna Town, Southern Ethiopia. Open Access Library Journal. 2015;2(01):1.

25. Mitiku A, Ayele TA, Assefa M, Tariku A. Undernutrition and associated factors among adults living with Human Immune Deficiency Virus in Dembia District, northwest Ethiopia: an institution based cross-sectional study. Archives of Public Health. 2016;74(1):33.

26. Weiser S, Palermo T, Rawat R, Weiser S, Kadiyala S. Food access and diet quality are associated with quality of life outcomes among HIV-infected individuals in Uganda. 2013.

27. Teshome MS, Gissa SB, Tefera BZ, Lema TB. Undernutrition and its predictors among people living with HIV/AIDS attending antiretroviral therapy clinic in Jimma University Specialized Hospital. International Journal of Nutrition and Metabolism. 2017;9(8):67-74.

28. Taruvinga A, Muchenje V, Mushunje A. Determinants of rural household dietary diversity: The case of Amatole and Nyandeni districts, South Africa. Int J Dev Sustainability. 2013;2(4):2233-47.

29. Muthamia OG, Mwangi AM, Mbugua SK. The effects of nutritional knowledge on the dietary practices of people living with HIV in Kayole division, Nairobi-Kenya. Int J Nutr Food Sci. 2014;3(6):597-601.

30. Powell B, Kerr RB, Young SL, Johns T. The determinants of dietary diversity and nutrition: ethnonutrition knowledge of local people in the East Usambara Mountains, Tanzania. Journal of ethnobiology and ethnomedicine. 2017;13(1):23.

31. Clausen T, Charlton KE, Gobotswang KS, Holmboe-Ottesen G. Predictors of food variety and dietary diversity among older persons in Botswana. Nutrition. 2005;21(1):86-95.

32. Ajani S. An assessment of dietary diversity in six Nigerian States. African Journal of Biomedical Research. 2010;13(3):161-7.

33. Kumera G, Tsedal E, Ayana M. Dietary diversity and associated factors among children of Orthodox Christian mothers/caregivers during the fasting season in Dejen District, North West Ethiopia. Nutrition \& Metabolism. 2018;15(1):16. 
34. Aemro M, Mesele M, Birhanu Z, Atenafu A. Dietary diversity and meal frequency practices among infant and young children aged 6-23 months in Ethiopia: a secondary analysis of Ethiopian demographic and health survey 2011. Journal of nutrition and metabolism. 2013;2013.

35. Sachdeva RK, Sharma A, Wanchu A, Dogra V, Singh S, Varma S. Dietary adequacy of HIV infected individuals in north India-A cross-sectional analysis. The Indian journal of medical research. 2011;134(6):967.

36. Adubra L, Savy M, Fortin S, Kameli Y, Kodjo NE, Fainke K, et al. The Minimum Dietary Diversity for Women of Reproductive Age (MDD-W) Indicator Is Related to Household Food Insecurity and Farm Production Diversity: Evidence from Rural Mali. 2019;3(3):nzz002.

37. Faber M, Wenhold FA, Laurie SM. Dietary diversity and vegetable and fruit consumption of households in a resource-poor peri-urban South Africa community differ by food security status. Ecology of food and nutrition. 2017;56(1):62-80.

\section{Tables}

Table 1: Socio-demographic and economic characteristics of adults on ART in Debre tabor Hospital, Northwest Ethiopia. 


\begin{tabular}{|c|c|c|}
\hline Variables & Frequency & Percent \\
\hline \multicolumn{3}{|l|}{ Age (Years) } \\
\hline $18-30$ & 77 & 22.9 \\
\hline $31-45$ & 181 & 53.9 \\
\hline $46-60$ & 66 & 20.5 \\
\hline$>60$ & 9 & 2.7 \\
\hline \multicolumn{3}{|l|}{ Sex } \\
\hline Male & 124 & 36.9 \\
\hline Female & 212 & 63.9 \\
\hline \multicolumn{3}{|l|}{ Marital status } \\
\hline Single & 51 & 15.2 \\
\hline Married & 147 & 43.8 \\
\hline Divorced & 102 & 30.4 \\
\hline Widowed & 36 & 10.7 \\
\hline \multicolumn{3}{|l|}{ Religion } \\
\hline Orthodox Christian & 334 & 99.4 \\
\hline Others & 2 & 0.6 \\
\hline \multicolumn{3}{|l|}{ Residence } \\
\hline Urban & 275 & 81.8 \\
\hline Rural & 61 & 18.2 \\
\hline \multicolumn{3}{|l|}{ Educational status } \\
\hline Unable to read and write & 49 & 14.6 \\
\hline Able to read and write & 40 & 11.9 \\
\hline Primary school & 86 & 25.6 \\
\hline Secondary school & 51 & 15.2 \\
\hline Diploma and above & 110 & 32.7 \\
\hline \multicolumn{3}{|l|}{ Occupational status } \\
\hline Government worker & 111 & 33.0 \\
\hline Private worker & 123 & 36.6 \\
\hline Unemployed & 102 & 30.3 \\
\hline \multicolumn{3}{|l|}{ Monthly income } \\
\hline$<600$ Ethiopian birr & 83 & 24.7 \\
\hline 600-1000 Ethiopian birr & 126 & 37.5 \\
\hline 1001-1750 Ethiopian birr & 44 & 13.1 \\
\hline >1750 Ethiopian birr & 83 & 24.7 \\
\hline
\end{tabular}

*Others $=$ Muslim and protestants

* 1 USD dollar= 28 Ethiopian birr

Table 2: Health and Nutrition related characteristics Adults on ART in Debre Tabor hospital, northwest Ethiopia. 


\begin{tabular}{|c|c|c|}
\hline Variables & Frequency & Percent \\
\hline \multicolumn{3}{|l|}{ WHO clinical staging } \\
\hline Stage I & 195 & 58 \\
\hline Stage II & 65 & 19.3 \\
\hline Stage III & 45 & 13.4 \\
\hline Stage IV & 31 & 9.2 \\
\hline \multicolumn{3}{|l|}{ CD4 Count } \\
\hline$<200$ cells $/ \mathrm{mm}^{3}$ & 50 & 14.9 \\
\hline 200-350cells $/ \mathrm{mm}^{3}$ & 54 & 16.1 \\
\hline 351-500cells $/ \mathrm{mm}^{3}$ & 54 & 16.1 \\
\hline$>500$ cells $/ \mathrm{mm}^{3}$ & 178 & 53 \\
\hline \multicolumn{3}{|l|}{ ART regimens } \\
\hline AZT based & 163 & 48.2 \\
\hline TDF based & 160 & 47.6 \\
\hline Second line & 14 & 4.2 \\
\hline \multicolumn{3}{|l|}{ Duration of ART } \\
\hline$<=18$ months & 31 & 9.2 \\
\hline 19-42months & 62 & 18.5 \\
\hline$>42$ months & 243 & 72.3 \\
\hline \multicolumn{3}{|c|}{ Opportunistic infections } \\
\hline Yes & 7 & 2.1 \\
\hline No & 329 & 97.9 \\
\hline \multicolumn{3}{|l|}{ Body mass index } \\
\hline$<18.5 \mathrm{~kg} / \mathrm{mm}^{2}$ & 77 & 22.9 \\
\hline$>=18.5 \mathrm{~kg} / \mathrm{mm}^{2}$ & 259 & 77.1 \\
\hline
\end{tabular}

Table 3: Bivariate and Multivariate analysis of factors associated with adequate dietary diversity among Adults on ART in Debre tabor Hospital, Northwest Ethiopia 


\begin{tabular}{|c|c|c|c|c|}
\hline \multirow[t]{2}{*}{ Variables } & \multicolumn{2}{|c|}{ DDS } & \multirow[t]{2}{*}{ COR (95\% CI) } & \multirow[t]{2}{*}{ AOR (95\% CI) } \\
\hline & Adequate & Inadequate & & \\
\hline \multicolumn{5}{|l|}{ Sex } \\
\hline Male & 50 & 73 & $0.6(0.35-0.89)$ & $0.7(0.43-1.22)$ \\
\hline Female & 59 & 154 & 1 & 1 \\
\hline \multicolumn{5}{|l|}{ Occupation status } \\
\hline Government employed & 25 & 86 & $2.2(1.22-4.03)$ & $2.5(1.28-4.98)^{* *}$ \\
\hline Private employed & 44 & 79 & $1.2(0.67-1.99)$ & $1.12(0.59-2.09)$ \\
\hline Unemployed & 40 & 62 & 1 & 1 \\
\hline \multicolumn{5}{|l|}{ Residence } \\
\hline Urban & 96 & 181 & $0.6(0.33-1.18)$ & $0.6(0.27-1.13)$ \\
\hline Rural & 15 & 46 & 1 & 1 \\
\hline \multicolumn{5}{|l|}{ Educational status } \\
\hline Unable to read and write & 19 & 30 & 1 & 1 \\
\hline Able to read and write & 18 & 22 & $0.7(0.33-1.81)$ & $0.6(0.23-1.56)$ \\
\hline Primary school & 30 & 56 & $1.2(0.57-2.44)$ & $1.03(0.44-2.29)$ \\
\hline Secondary school & 22 & 29 & $0.8(0.38(-1.86)$ & $0.7(0.29-1.71)$ \\
\hline Diploma and above & 20 & 90 & $2.6(1.34-6.04)$ & $2.3(1.01-5.31)^{* *}$ \\
\hline \multicolumn{5}{|l|}{ Monthly income } \\
\hline$<600$ Ethiopian birr & 20 & 63 & 1 & 1 \\
\hline 600-1000Ethiopian birr & 40 & 86 & $0.7(0.36-1.28)$ & \\
\hline 1001-1750Ethiopian birr & 12 & 32 & $0.8(0.37-1.95)$ & \\
\hline$>=1750$ Ethiopian birr & 37 & 46 & $0.4(0.20-0.77)$ & \\
\hline
\end{tabular}

**indicate that significant with the p-value $<0.05$

* 1 USD dollar= 28 Ethiopian birr 